\title{
SYSTEM DYNAMICS MODEL BASED ON EVOLUTIONARY GAME THEORY FOR QUALITY SUPERVISION AMONG CONSTRUCTION STAKEHOLDERS
}

\author{
Shengyu GUO ${ }^{1}$, Pan $\mathrm{ZHANG}^{2}$, Jianying $\mathrm{YANG}^{3}$ \\ ${ }^{1}$ School of Economics and Management and Institute of Management Science and Engineering, \\ China University of Geosciences, Wuhan, China \\ ${ }^{2}$ School of Civil Engineering and Mechanics and Institute of Construction Management, \\ Huazhong University of Science and Technology, Wuhan, China \\ ${ }^{3}$ Wuhan Center of China Geological Survey, Wuhan, China
}

Received 23 September 2017; accepted 07 May 2018

\begin{abstract}
To address the gap, that is, few studies have explored the influence of the participants' interactions with one another during construction quality supervision, this paper proposes a system dynamics model based on evolutionary game theory to describe the complex and dynamic interactions among tripartite stakeholders in China, including the project owner (PO), construction supervising engineer (CSE), and construction contractor (CC). First, the replicated dynamic equation set is established in terms of expense targets. Second, the equilibrium solutions of the equation set are obtained to test strategy options. The trends of system fluctuations caused by penalty and reward changes are also analyzed. Finally, the stability of the proposed model is improved by integrating a dynamic penalty-reward scenario into the evolutionary strategy of the PO. Simulation results show that: 1) the evolutionary stable strategy does not exist in initial interactions, 2) the degrees of penalty and reward considerably affect the CC's rate variable, and 3) the dynamic penalty-reward scenario could effectively improve the stability of the proposed model. The unsteadiness of the quality supervision system and the stability control scenario could help in understanding the impact of interactions among stakeholders and provide suggestions for optimizing quality supervision procedures.
\end{abstract}

Keywords: construction quality, quality supervision, tripartite stakeholders, evolutionary game theory, system dynamics, dynamic penalty-reward.

\section{Introduction}

The construction industry is often criticized for its poor performance on quality (Kanji, Wong 1998). Quality in its simplest form could be defined as: "meeting the customer's expectations" or "compliance with the customer's specification" (Jha, Iyer 2006). Compared with other industries, construction procedures entail much concealed work, which leads to the limited effect of final quality detection (Arditi, Gunaydin 1997). To meet the owner's expectation, quality in construction not only means physical quality but also represents working quality. Organization is one of the most critical factors affecting working quality (Chan et al. 2004). Its influence is mainly reflected in two aspects: 1) the degree of standardized construction and 2) the strength of supervision. The first one is related to the construction contractor (CC). The second one involves other types of participants, namely, the project owner
$(\mathrm{PO})$ and the construction supervising engineer (CSE) in China (Wang, Huang 2006). According to China's Regulation on the Quality Management of Construction Projects, the PO should entrust quality management tasks to the CSE. The CSE represents the interests of the PO in terms of construction quality. Moreover, the $\mathrm{CC}$ is responsible for construction quality, whereas the PO and CSE have supervision responsibilities. Compared with their counterparts in other countries, the PO and CC in China have similar responsibilities in the quality supervision process, whereas the CSE differs in some respects. The specific differences are shown in Table 1.

The CSE provides consultant services in quality supervision. In developed countries, supervision works are comprehensive, and they consider entire process services, high technical requirements, and good profits. Therefore,

*Corresponding author. E-mail: zhangpan2017@hust.edu.cn 
Table 1. Differences of the CSE in various countries

\begin{tabular}{|ccccc|}
\hline Country & Scope of work & Compulsory & Technical level & Profits $^{\mathrm{a}}(\%)$ \\
\hline China & Construction stage & All projects & Low & $0.6-3$ \\
America & Whole process & Government projects & High & $6-15$ \\
German & Whole process & All projects & High & $7-14$ \\
Britain & Whole process & Most projects & High & $8.85-13.25$ \\
Japan & Whole process & Projects above a certain scale & High & 3 \\
\hline
\end{tabular}

a The profit is based on total engineering cost.

on average, the construction quality in developed countries is better than that in China. Unlike their peers in developed countries, CSEs in China are chiefly responsible for supervision in the construction stage, with a focus on quality and safety. Their consultant service is limited, and they are unable to achieve maximum effectiveness. In China, a CSE's low technical level leads to poor efficiency, and low profits lead to less R\&D investment and slow technical progress, which forms a vicious cycle between efficiency and technical level. In addition, even if a PO is unsatisfied with the performance of a CSE, it cannot dismiss the CSE because of the mandatory provision of the government, which worsened the relationship between the PO and CSE. Paradoxically, the PO is rarely involved in quality supervision because it considers the CSE responsible for quality. In summary, these factors generate the complexity regarding the influence of participants in quality supervision and increase the uncertainty of stakeholders' behavior. For example, contractors receive payment from owners, so they are more compliant toward owners than toward engineers when quality problems occur (Chen, Partington 2004). Moreover, some contractors engage in jerry-building to obtain illegal and additional benefits. Instead of providing strict supervision, some engineers seek rent from contractors and even cheat owners with contractors (Wang et al. 2014). Furthermore, some owners do not have sufficient professional skills to handle their work, so they rely heavily on engineers for quality supervision (Huang et al. 2008). All these problems reflect the negative interactions between the tripartite stakeholders of the PO, CSE, and CC in the quality supervision process. Existing studies merely analyze the impact of such interactions on quality performance. However, quality in the construction stage could only be achieved through the direct efforts of all stakeholders. Therefore, the identification of critical factors that affect conflicts and collaborations among stakeholders and provide solutions to optimize the procedures of quality supervision are of theoretical and practical significance.

Game theory involves studying the mathematical models of conflict and cooperation on multi-person interactions, which could help explore behavioral relations among stakeholders in the quality supervision process. Existing literature on game theory applications in construction has mainly entail dispute resolution (San Cristóbal 2015; Khanzadi et al. 2016), risk management (Li et al. 2016; Nasirzadeh et al. 2016), and resource management (Sacks, Harel 2006); in addition, most of them ap- plied classical game theory to solve problems. However, game theory involves an important hypothesis on the players, that is, the players are intelligent and rational, which is inconsistent with the actual situation. Compared with classical game theory, evolutionary game theory combines game theory with dynamic evolution process analysis, and it focuses more on the dynamics of strategy change (Weibull 1997). Evolutionary game theory aims at finding stable strategies in any area with conflict of interests (Parsapour-Moghaddam et al. 2015). Tripartite stakeholders involved in quality supervision are bounded and rational, and they change and adjust their strategies dynamically by observing and comparing payoffs with others. Therefore, evolutionary game theory is more suitable for studying the long-term dynamic game among tripartite stakeholders in quality supervision in China. To analyze the feedback structure of the game, some studies used system dynamics (SD) to analyze the evolutionary stable strategy (ESS) and achieved good results (e.g. Tian et al. 2014; Liu et al. 2015; Duan et al. 2016). Hence, SD can provide a solution to balance the interests of tripartite stakeholders and improve quality supervision work.

To bridge the gap in extant research, this paper proposes an SD model based on evolutionary game theory to analyze the evolutionary game for quality supervision among tripartite stakeholders, which includes the PO, CSE, and CC. First, the relationships among tripartite stakeholders were described and assumed according to organizational problems. Second, a replicated dynamic equation set was established based on behavior strategies in terms of expense targets, which reflects the strategy adjustments of the PO, CC, and CSE. Third, equilibrium solutions were ascertained. Fourth, the stability of the equilibrium solutions and the influence of external variables were analyzed through simulations of the SD model. Finally, the ESS was identified under the dynamic penalty-incentive scenario. A framework of the proposed model is presented in Figure 1.

In summary, the proposed model was applied to identify the behavior rules of the PO, CC, and CSE in the quality supervision process and ascertain their influence on one another through simulations. This research aims to prove the irrational problems among tripartite stakeholders in the Chinese quality supervision organization and explore practical solutions to optimize the quality supervision mode based on the outcomes of the suggested model. 


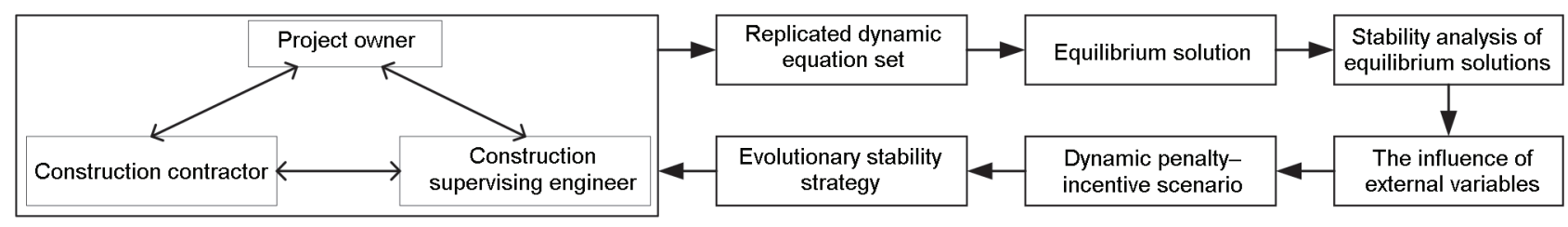

Figure 1. Framework of the proposed model

\section{Literature review}

\subsection{Quality management in the construction industry}

Quality management comprises all the activities that managers perform to implement their quality policy (Harris, McCaffer 2013). In the construction industry, numerous efforts have been made regarding quality management, including those in quality assurance (QA), quality control (QC), and total quality management (TQM). Although often used interchangeably, the terms QA and QC are distinct as QA emphasizes defect prevention, whereas QC focuses on defect detection. The principles of QA, such as ISO 9001, have been virtually regarded as essential in today's construction industry (Harris, McCaffer 2013). Moreover, some traditional methods have been further developed for QC, such as Six Sigma (Tchidi et al. 2012). Technical improvements have also been made to enhance the efficiency and effectiveness of QA and QC during construction, including information systems (Love, Irani 2003; Cheng et al. 2015), BIM (Chen, Luo 2014), thermography (Taylor et al. 2013), laser scanning (Bosché 2010), and RFID (Lu et al. 2011). TQM is based on the philosophy of continuously improving goods or services, including in construction (Pheng, Teo 2004). Some studies have confirmed the gradual adoption and utilization of TQM by construction companies to solve quality problems (Arditi, Gunaydin 1997; Wong 1999; Pheng, Teo 2004). Despite the positive developments, barriers must still be overcome to achieve better quality. Some of those impediments are within the organizations involved in construction. Loushine et al. (2006) revealed that "shoddy" implementation as an obstacle to the success of quality management in construction projects. Talib et al. (2011) found that employee resistance to change hindered TQM implementation. Abdul-Aziz (2002) indicated the non-direct link between the main contractors and site operatives as a constraining factor affecting construction quality. Some barriers are reflected in conflicts among construction participants (Jha, Iyer 2006; Hoonakker et al. 2010; Toor, Ogunlana 2010). Several studies have provided solutions to overcome these hindrances. For example, Love et al. (2000) proposed a framework of learning organization to continually improve TQM. Meng (2012) confirmed that the adoption of supply chain collaboration and partnering helped solve the quality performance problem. Eriksson and Westerberg (2011) suggested that cooperative procurement procedures positively influence project quality. Furthermore, Dikmen et al. (2005) argued that quality function deployment could remove function barriers among departments. In addition, some studies have examined the impact of specific stakeholders (e.g. contractor and vendor) on quality management and provided suggestions for further amelioration (Doloi et al. 2011; Sullivan 2011; Alzahrani, Emsley 2013). Thus, an organization acts as a critical factor affecting quality performance. Solutions and recommendations from the literature have primarily focused on the change management patterns and procedures of certain stakeholders. However, quality problems are sometimes caused by inadequate or unethical behaviors of stakeholders in construction activities, and few studies have analyzed the impact of negative interactions among stakeholders on quality.

Quality supervision, which primarily influences the overall performance and efficiency of construction projects, is a specific procedure of QC (O'Brien 2013). The PO, CSE, and CC are tripartite stakeholders involved in quality supervision. The impact of their behaviors in their interaction with one other needs to be clarified, and thus, appropriate suggestions could be made to build trust and reduce conflict in the supervision activities.

\subsection{Applications of system dynamics based on evolutionary game theory}

Evolutionary game theory is one of the most fruitful frameworks for studying evolution in different disciplines (Roca et al. 2009). It was developed to overcome the disadvantages of traditional game theory when analyzing the bounded rationality of players and the dynamic process of game playing. SD was adopted to study the stability of the equilibrium solution by analyzing the feedback behaviors among stakeholders in the game. Several studies have combined SD with evolutionary game theory to evaluate and resolve problems in various areas, including supply chain, commercial domains, environmental pollution, and safety. For example, Tian et al. (2014) analyzed the relationships of stakeholders as government, enterprises, and consumers through evolutionary game theory and developed an SD model to promote the diffusion of green supply chain management in China. Similarly, Zhang (2016) constructed a dynamic evolutionary game model to study equilibrium stability in the game between commercial banks and closed-loop supply chain (CLSC) enterprises. Besides, Wang et al. (2011) proposed an SD model for examining a mixed-strategy evolutionary game of environmental pollution between the government and a firm. Liu et al. (2015) explored dynamic simulations of the evolutionary game model to assess the stability of stakeholder interactions in a coal mine safety inspection system. 
The aforementioned applications reveal that the combination of evolutionary game theory with the SD method is suitable for simulating dynamic games, and thus has potential for describing the interactions among tripartite stakeholders and further identify equilibrium solutions in quality supervision.

\section{Evolutionary game analysis of construction quality supervision}

In the construction quality supervision in China, tripartite stakeholders behave as bounded rational players, and their information is asymmetric. Specifically, the stakeholders cannot always make the right decisions under limited information. Moreover, the CSE spends most of the time working in the construction site to obtain more information about the CC than the PO. In repetitious games, stakeholders change their strategies dynamically by observing and comparing payoff with others and then adjusting their strategies. Therefore, evolutionary game theory was adopted to study the long-term dynamic game among the said stakeholders.

\subsection{Game relationship description and assumption}

Given the actual situation of construction in China, the game relationship of the tripartite stakeholders in quality supervision is described as follows:

- The PO supervises the CSE and CC. Its strategy choices can be supervised or unsupervised as regards ensuring construction quality and supervision cost.

- The CSE regulates the CC. Its strategy choices can be executed as regulation duties or not in view of punishment from the PO and additional benefits (rentseeking) from the CC.

- The CC is under the supervision of the PO and CSE in relation to quality. Its strategy choices can be strictly implemented as standardized construction or non-standardized construction (e.g. jerry-building and using substandard materials).

Bribery behavior is assumed to exist between the CSE and CC, but not between the PO and CC. Therefore, the behavior information between the CSE and CC is incomplete. The other assumption is that the PO and CSE's ability of supervision is sufficiently powerful, and they could find all the situations of non-standardized construction by the CC.

\subsection{Game equation definition and analysis}

To represent the supervision strategy by the PO in the evolutionary game model, $x(0 \leq x \leq 1)$ is designated as the supervision ratio. When $x=0$ or 1 , then no supervision or real-time supervision is made on the CC and CSE. However, decisions about the supervision strategy have cost implications. Real-time supervision cost is high, so limited times of supervision are practical. Therefore, the PO must pay a cost when supervising the CC's construction situations and the CSE's execution of regulation duties. During supervision, $C_{a}\left(C_{a}>0\right)$ represents the PO's supervision cost, $L_{a}\left(L_{a}>0\right)$ indicates the PO's expected loss caused by malpractice, and $P_{b}\left(P_{b}>0\right)$ and $R_{b}\left(R_{b}<P_{b}\right)$ denote the CC's penalties and rewards from the PO, respectively. Moreover, the CSE will be punished because of dereliction of regulation duties or be given rewards when regulating the CC strictly, that is, $P_{c}\left(P_{c}>0\right)$ and $R_{c}\left(R_{c}<P_{c}\right)$ signify the CSE's penalties and rewards, respectively.

The CC chooses $y(0 \leq y \leq 1)$ as its strategy during construction, in which y represents the standardized construction ratio. The degree of standardized construction by the CC is increased from 0 to 1 . In the CC's construction activities, $N_{b}\left(N_{b}>0\right)$ indicates the profits from standardized construction, whereas $C_{b}\left(C_{b}>0\right)$ denotes the quality cost. If the $\mathrm{CC}$ chooses non-standardized construction, some quality cost will be saved and the probability of project quality defects or accidents will be increased, which will result in expected loss. Such expected loss includes not only the cost of rework or requirement, but also rentseeking to the CSE, in which $S_{b}\left(S_{b}<C_{b}\right)$ and $F_{b}\left(F_{b}<S_{b}\right)$ signify total expected losses under successful and unsuccessful rent-seeking, respectively.

The CSE chooses $z(0 \leq z \leq 1)$ as their strategy when regulating the CC's construction situation, in which $z$ represents regulation ratio. When $z=0$, dereliction of regulation duties and even power rent-seeking transpired, and $z=1$ denotes the strict execution of regulation duties. During regulation, $N_{c}\left(N_{c}>0\right)$ represents the profits for quality regulation work of the CSE. If the CSE chooses the dereliction of regulation duties and even power rent-seeking, then it will gain rent from the CC, but it will simultaneously incur an expected loss when the PO investigates and assigns responsibility, and $E_{c}\left(L_{c}<E_{c}<S_{b}\right)$ and $L_{c}\left(L_{c}>0\right)$ symbolize net rents and expected loss, respectively.

The payoff matrix among tripartite stakeholders is shown in Figure 2 according to the pre-defined variables above.

\subsection{Game equation solution and application}

According to evolutionary game theory, bounded rational players tend to choose those strategies whose fitness or payoff is better than the other strategies on replicator dynamics. By constantly imitating and learning, players will achieve a balance between anti-interference and stability. Consequently, the PO's supervision fitness and no-supervision fitness can be obtained as follows:

$$
\begin{gathered}
U_{x}=\left(\begin{array}{l}
y z\left(-C_{a}-R_{b}-R_{c}\right)+(1-y) z\left(-C_{a}+P_{b}-R_{c}\right)+ \\
y(1-z)\left(-C_{a}-R_{b}+P_{c}\right)+ \\
(1-y)(1-z)\left(-C_{a}+P_{b}+P_{c}\right)
\end{array}\right) \\
=-C_{a}+P_{b}+P_{c}-y\left(P_{b}+R_{b}\right)-z\left(\mathrm{P}_{c}+R_{c}\right) ; \\
U_{1-x}=\left(\begin{array}{l}
y z * 0+(1-y) z\left(-L_{a}\right)+ \\
y(1-z) * 0+(1-y)(1-z)\left(-L_{a}\right)
\end{array}\right)= \\
\quad-(1-y) *\left(-L_{a}\right),
\end{gathered}
$$

where $U_{x}$ is supervision fitness, and $U_{1-x}$ is no-supervision 


\begin{tabular}{|c|c|c|c|c|c|c|}
\hline & \multirow[b]{2}{*}{$\begin{array}{l}\text { Execution of } \\
\text { regulation duties }\end{array}$} & \multicolumn{3}{|c|}{ Construction supervising engineer } & & \multirow[b]{2}{*}{$\begin{array}{l}\text { Dereliction of } \\
\text { regulation duties }\end{array}$} \\
\hline & & & & & & \\
\hline \multirow{2}{*}{$\begin{array}{l}\text { Project } \\
\text { owner }\end{array}$} & \multicolumn{2}{|c|}{ Construction contractor } & \multirow{2}{*}{$\begin{array}{l}\text { Project } \\
\text { owner }\end{array}$} & \multicolumn{3}{|c|}{ Construction contractor } \\
\hline & $\begin{array}{l}\text { Standardized } \\
\text { construction }\end{array}$ & $\begin{array}{l}\text { Nonstandardized } \\
\text { construction }\end{array}$ & & $\begin{array}{r}\text { Stan } \\
\text { const }\end{array}$ & $\begin{array}{l}\text { ardized } \\
\text { uction } 1\end{array}$ & $\begin{array}{c}\text { Nonstandardized } \\
\text { construction }\end{array}$ \\
\hline Supervision & $\begin{array}{c}-\mathrm{C}_{\mathrm{a}}-\mathrm{R}_{\mathrm{b}}-\mathrm{R}_{\mathrm{c}} \\
\mathrm{N}_{\mathrm{b}}+\mathrm{R}_{\mathrm{b}}, \quad \mathrm{N}_{\mathrm{c}}+\mathrm{R}_{\mathrm{c}}\end{array}$ & $\begin{array}{c}-\mathrm{C}_{\mathrm{a}}+\mathrm{P}_{\mathrm{b}}-\mathrm{R}_{\mathrm{c}} \\
\mathrm{N}_{\mathrm{b}}-\mathrm{P}_{\mathrm{b}}-\mathrm{F}_{\mathrm{b}}+\mathrm{C}_{\mathrm{b}}, \quad \mathrm{N}_{\mathrm{c}}+\mathrm{R}_{\mathrm{c}}\end{array}$ & Supervision & $\begin{array}{r}-\mathrm{C}_{\mathrm{a}}- \\
\mathrm{N}_{\mathrm{b}}+\mathrm{R}_{\mathrm{b}}\end{array}$ & $\begin{array}{l}\mathrm{b}+\mathrm{P}_{\mathrm{c}} \\
\mathrm{N}_{\mathrm{c}}-\mathrm{P}_{\mathrm{c}}-\mathrm{L}_{\mathrm{c}}\end{array}$ & $\begin{array}{r}-\mathrm{C}_{\mathrm{a}}+\mathrm{P}_{\mathrm{b}}+\mathrm{P}_{\mathrm{c}} \\
\mathrm{N}_{\mathrm{b}}-\mathrm{P}_{\mathrm{b}}-\mathrm{S}_{\mathrm{b}}+\mathrm{C}_{\mathrm{b}} \\
\mathrm{N}_{\mathrm{c}}-\mathrm{P}_{\mathrm{c}}-\mathrm{L}_{\mathrm{c}}+\mathrm{E}_{\mathrm{c}}\end{array}$ \\
\hline No supervision & $0, \quad \mathrm{~N}_{\mathrm{b}}, \quad \mathrm{N}_{\mathrm{c}}$ & $-\mathrm{L}_{\mathrm{a}}, \quad \mathrm{N}_{\mathrm{b}}-\mathrm{F}_{\mathrm{b}}+\mathrm{C}_{\mathrm{b}}, \quad \mathrm{N}_{\mathrm{c}}$ & No supervision & $0, \quad \mathrm{~N}_{\mathrm{l}}$ & $\mathrm{N}_{\mathrm{c}}-\mathrm{L}_{\mathrm{c}}$ & $\begin{array}{c}-\mathrm{L}_{\mathrm{a}}, \quad \mathrm{N}_{\mathrm{b}}-\mathrm{P}_{\mathrm{b}}+\mathrm{C}_{\mathrm{b}}, \\
\mathrm{N}_{\mathrm{c}}-\mathrm{L}_{\mathrm{c}}+\mathrm{E}_{\mathrm{c}}\end{array}$ \\
\hline
\end{tabular}

Figure 2. Payoff matrix of the PO, CC and CSE

fitness. Thus, the average fitness of the PO can be obtained as follows:

$$
\bar{U}_{x, 1-x}=x U_{x}+(1-x) U_{1-x} .
$$

In the evolutionary game, the PO tends to learn and imitate strategies of higher fitness. The higher the strategy's fitness is, the higher the probability of it being chosen. According to the replicator dynamics, the change rate of $x$ is as follows:

$$
\begin{aligned}
\frac{d x}{d t}= & x\left(U_{x}-\bar{U}_{x, 1-x}\right)=x\left(U_{x}-\left(x U_{x}+(1-x) U_{1-x}\right)=\right. \\
& x(1-x)\left(U_{x}-U_{1-x}\right) .
\end{aligned}
$$

By defining $F(x, y, z)=d x / d t$ and bringing Eqns (1) and (2) into Eqn (4), we obtain Eqn (5) or the PO's replicated dynamic equation as follows:

$$
\begin{aligned}
& F(x, y, z)=x(1-x) \\
& \left(\begin{array}{l}
y z\left(-C_{a}-R_{b}-R_{c}\right)+(1-y) z\left(-C_{a}+P_{b}-R_{c}+L_{a}\right)+ \\
y(1-z)\left(-C_{a}-R_{b}+P_{c}\right)+ \\
(1-y)(1-z)\left(-C_{a}+P_{b}+P_{c}+L_{a}\right)
\end{array}\right) .
\end{aligned}
$$

Similarly, the change rates of $y$ and $z$ are respectively, are as follows:

$$
\begin{aligned}
& H(x, y, z)=\frac{d y}{d t}=y(1-y) \\
& \left(\begin{array}{l}
x z\left(R_{b}+P_{b}+F_{b}-C_{b}\right)+(1-x) z\left(F_{b}-C_{b}\right)+ \\
x(1-z)\left(R_{b}+P_{b}+S_{b}-C_{b}\right)+(1-x)(1-z)\left(S_{b}-C_{b}\right)
\end{array}\right) \\
& G(x, y, z)=\frac{d z}{d t}=z(1-z) \\
& \left(\begin{array}{l}
x y\left(R_{c}+P_{c}+L_{c}\right)+(1-x) y L_{c}+ \\
x(1-y)\left(R_{c}+P_{c}+L_{c}-E_{c}\right)+(1-x)(1-y)\left(L_{c}-E_{c}\right)
\end{array}\right) .
\end{aligned}
$$

Therefore, the dynamic interaction of tripartite stakeholders could be represented by a replicated dynamic equation set composed of Eqns (5), (6), and (7), which reflects the speed and direction of the strategy adjustment of the PO, CC, and CSE. When the equation set is equal to zero, it means that the strategy will not be changed and the evolutionary game system reaches a relatively stable equilibrium state. Furthermore, the stability of the equilibrium solution could be analyzed by calculating the Jacobian matrix's determinant and trace of the game, which reflects the existence of the ESS. The Jacobian matrix is as follows:

$$
J=\left(\begin{array}{lll}
\frac{\partial F(x, y, z)}{\partial x} & \frac{\partial F(x, y, z)}{\partial x} & \frac{\partial F(x, y, z)}{\partial x} \\
\frac{\partial G(x, y, z)}{\partial x} & \frac{\partial G(x, y, z)}{\partial x} & \frac{\partial G(x, y, z)}{\partial x} \\
\frac{\partial H(x, y, z)}{\partial x} & \frac{\partial H(x, y, z)}{\partial x} & \frac{\partial H(x, y, z)}{\partial x}
\end{array}\right)
$$

According to Friedman's theory (Friedman 1991), when the Jacobian matrix's determinant $\operatorname{Det}(J)>0$ and its trace $\operatorname{Tr}(J)<0$, the equilibrium solution is the ESS. Given the amount and tediousness of calculations, a computer simulation method could be considered to provide decision support for a complicatedly dynamic multi-player game.

\section{Analysis of a system dynamics model of construction quality supervision}

System dynamics is an effective simulation method to understand the behavior of complex systems over time, mainly by analyzing the causality and interaction among different variables within the system (Vlachos et al. 2007). Considering its advantages in solving problems with incomplete information, the evolutionary game process under bounded rationality could be well simulated with SD. Then, the existence or absence of ESS could be identified. 


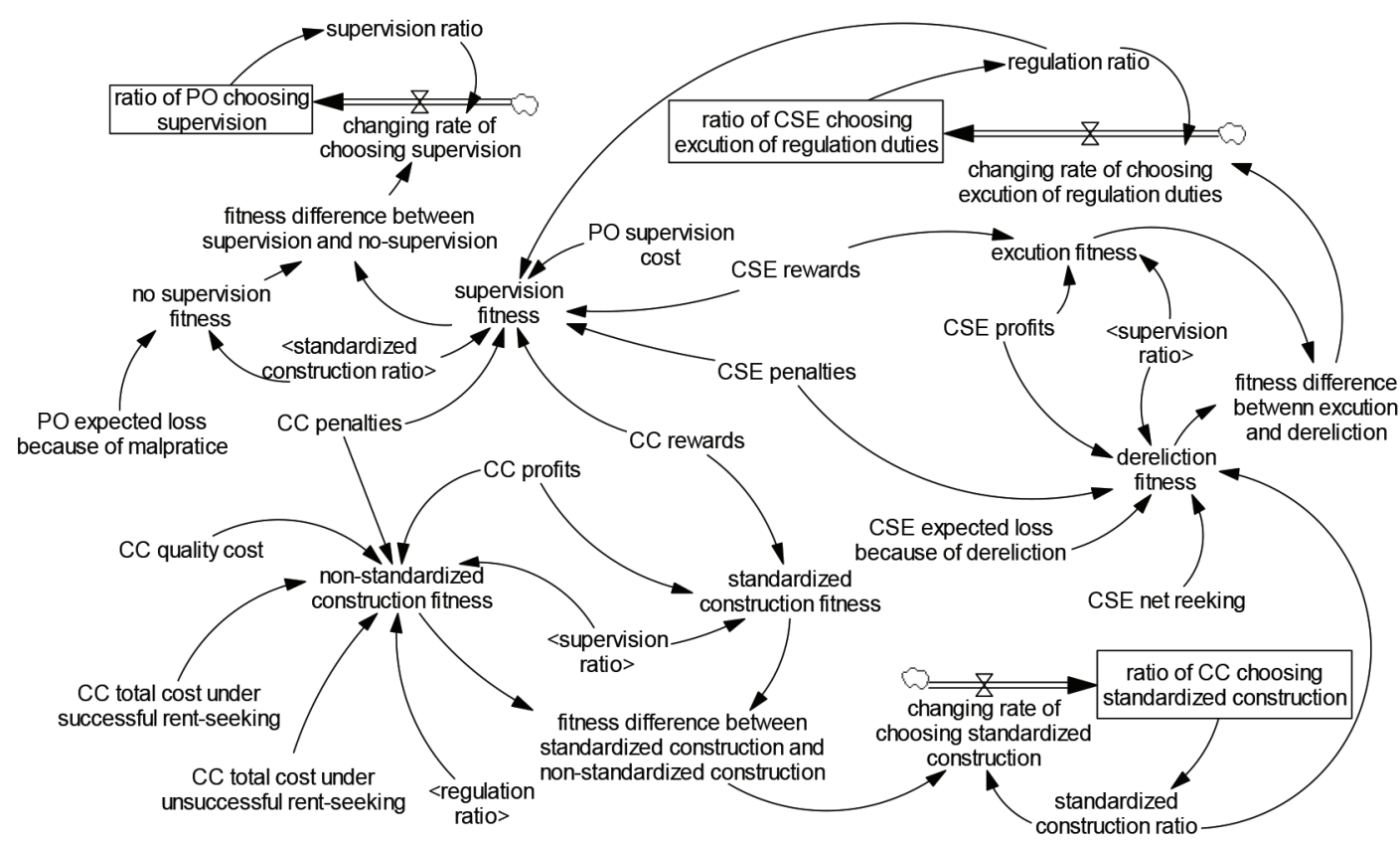

Figure 3. Evolutionary game SD model of construction quality supervision

Moreover, the tripartite stakeholders' behavior changes could be presumed by changing external variables.

\subsection{Description and development of the system dynamics model}

By using Vensim PLE Version 6.3, the evolutionary game SD model was established according to the above game equation assumption and analysis, as shown in Figure 3.

The SD model has 3 level variables, 3 rate variables, 12 auxiliary variables, and 13 external variables. Level variables involve the accumulations (i.e., ratio of PO choosing supervision) within the system. Rate variables represent the flows in the system (i.e., changing rate of choosing supervision) caused by the decision-making process. Auxiliary variables refer to transition variables by calculation (i.e., supervision fitness), whereas external variables entail the constants in the system (i.e., PO supervision cost). The functional relationship among these variables relies on the above replicated dynamic equation set of the game system.

\subsection{Simulation and analysis of system dynamics model}

The model settings are: INITIAL TIME $=0$, FINAL TIME $=100$, TIME STEP $=0.03125$, Units for Time: Month, Integration Type: Euler. According to the China Construction Industry Statistical Yearbook, the initial values of external variables in the SD model are shown in Table 2 .

Therefore, the equilibrium solutions of the replicated dynamic equation set (8) are obtained as follows, namely, eight and two equilibrium solutions of pure and mixed strategies, respectively:

Table 2. Initial values of external variables in the SD model

\begin{tabular}{|clc|}
\hline Variables & \multicolumn{1}{c|}{ Meaning of the variables } & Initial values \\
\hline$C_{\mathrm{a}}$ & PO supervision cost & 1 \\
$L_{a}$ & PO expected loss because of malpractice & 4 \\
$N_{b}$ & CC profits & 10 \\
$C_{b}$ & CC quality cost & 4 \\
$P_{b}$ & CC penalties & 4 \\
$R_{b}$ & CC rewards & 2 \\
$S_{b}$ & CC total cost under successful rent-seeking & 2 \\
$F_{b}$ & CC total cost under unsuccessful rent-seeking & 1 \\
$N_{c}$ & CSE profits & 5 \\
$E_{c}$ & CSE net rent & 1.5 \\
$L_{c}$ & CSE expected loss because of dereliction & 0.5 \\
$P_{c}$ & CSE penalties & 2 \\
$R_{c}$ & CSE rewards & 1 \\
\hline
\end{tabular}




$$
\begin{aligned}
& \lambda_{1}=\left(\begin{array}{l}
0 \\
0 \\
0
\end{array}\right), \lambda_{2}=\left(\begin{array}{l}
0 \\
1 \\
0
\end{array}\right), \lambda_{3}=\left(\begin{array}{l}
0 \\
0 \\
1
\end{array}\right), \lambda_{4}=\left(\begin{array}{l}
0 \\
1 \\
1
\end{array}\right), \lambda_{5}=\left(\begin{array}{l}
1 \\
0 \\
0
\end{array}\right) ; \\
& \lambda_{6}=\left(\begin{array}{l}
1 \\
1 \\
0
\end{array}\right), \lambda_{7}=\left(\begin{array}{l}
1 \\
0 \\
1
\end{array}\right), \lambda_{8}=\left(\begin{array}{l}
1 \\
1 \\
1
\end{array}\right), \lambda_{9}=\left(\begin{array}{c}
1 / 3 \\
10 / 11 \\
0
\end{array}\right), \lambda_{10}=\left(\begin{array}{c}
1 / 2 \\
7 / 11 \\
1
\end{array}\right) .
\end{aligned}
$$

\subsection{Stability analysis of equilibrium solutions}

For example, $\lambda_{9}$ is incorporated into the SD model for simulation, and the game result is shown in Figure 4. Note that tripartite stakeholders do not actively change their initial strategies and no one adopts a new strategy, which reflects a relatively balanced state.

However, this relatively balanced state is unsteady. If the CSE in $\lambda_{9}$ mutates their initial strategy, that is, the ratio of $z$ in $\lambda_{9}$ changes from 0 to 0.01 , then the game could be simulated again (results are shown in Figure 5). The simulation result shows unsteadiness because the strategy selection of the CSE evolves gradually toward $z=1$, whereas the strategy selections of the other two fluctuate repeatedly. Similarly, the balanced states of the mixed strategy $\lambda_{10}$ and other pure strategies are also unsteady according

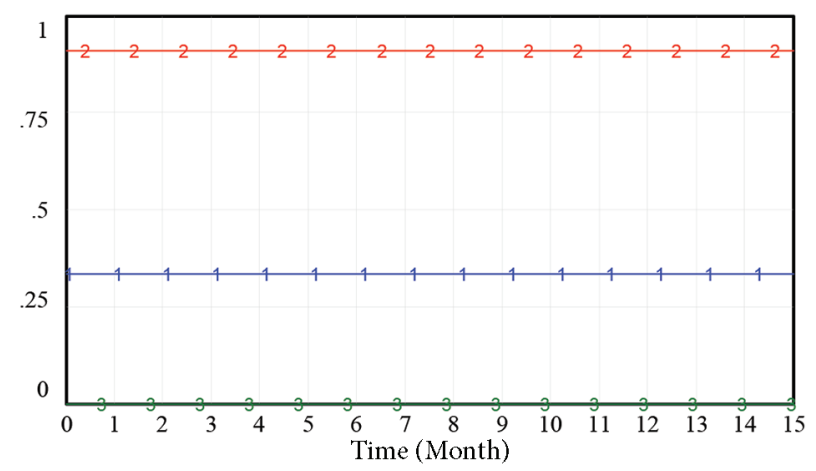

$\mathrm{x}(\mathrm{x}=1 / 3, \mathrm{y}=10 / 11, \mathrm{z}=0) \quad 1,1,1,1,1,1,1,1,1$, $y(x=1 / 3, y=10 / 11, z=0) \quad 2 \quad 22^{2} z_{2} 2_{2}^{2} 2$

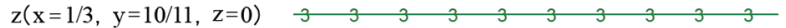

Figure 4. Game result under initial strategy $\lambda_{9}$

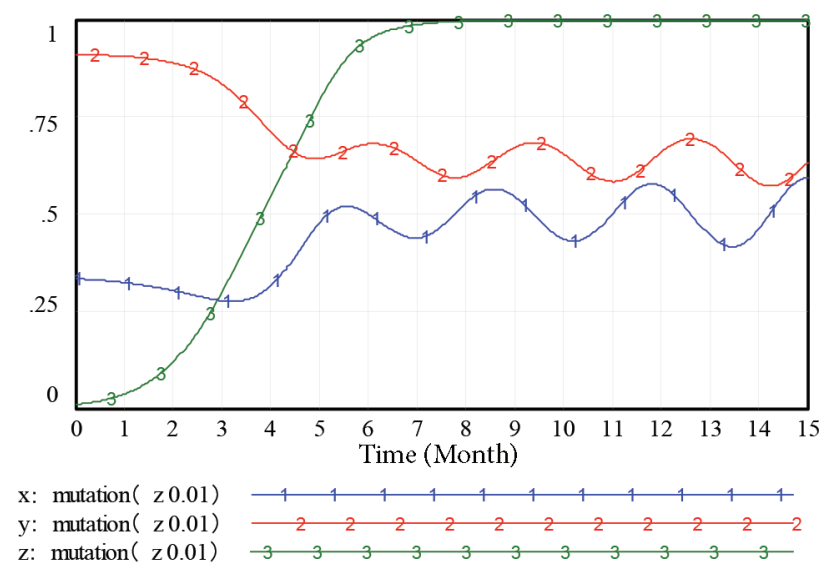

Figure 5. Game results exist mutation $\left(\lambda_{9}\right)$ to the simulation results. In conclusion, no ESS is present in the game played.

\subsection{Influence of external variables on the system dynamics model}

The existing fluctuations make it difficult to control construction quality. Therefore, the fluctuations should be controlled in the game playing or force game process to reach a certain state of stability. In the model, external variables act as critical factors affecting the fluctuations. Among these external variables, penalty and reward are relatively easier to adjust in actual situations; thus, their influences are examined. To compare the degree of their influences, a hypothesis that $x, y$, and $z$ are equal to 0.5 is proposed under initial conditions. The simulation results are shown in Figure 6.

First, the influence of penalty is discussed. After increasing penalties of the CC and CSE, that is, $P_{b}$ changes from 4 to 6 and $P_{c}$ changes from 2 to 3 , the game results are shown in Figures 7 and 8. Comparison with Figure 6 reveals that increasing the penalty of the CC cannot decrease the equilibrium point of the game process, but in the long term, it allows the game system to reach a stable state of $x=0, y=1$, and $z=1$ in advance. By contrast, increasing the penalty of the CSE has no influence on the fluctuations

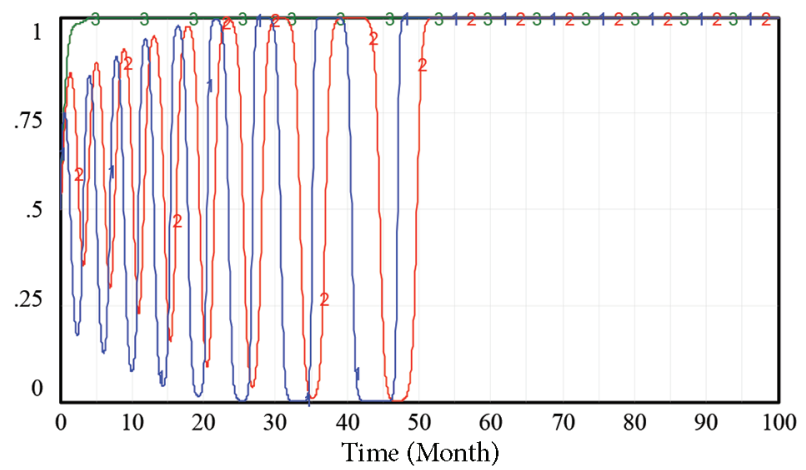

$\mathrm{x}(\mathrm{x}=0.5, \mathrm{y}=0.5, \mathrm{z}=0.5) \quad \mathrm{1}, \mathrm{1}, \mathrm{1}, \mathrm{1}, 1,1,1+$ $\mathrm{y}(\mathrm{x}=0.5, \mathrm{y}=0.5, \mathrm{z}=0.5) \quad \begin{array}{llllllllll}2 & 2 & 2 & 2 & 2 & 2 & 2 & 2 & 2\end{array}$ $z(x=0.5, y=0.5, z=0.5) \quad-3 \quad 3 \quad \begin{array}{llllllll}3 & 3 & 3 & 3 & 3 & 3 & 3 & 3\end{array}$

Figure 6. Game results under the initial hypothesis

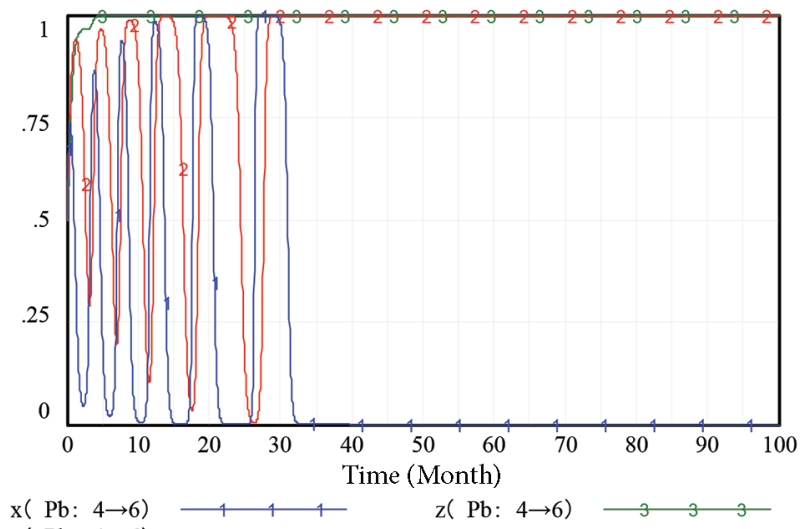

$\mathrm{y}(\mathrm{Pb}: 4 \rightarrow 6) \quad 2 \quad 2 \quad 2 \quad 2$

Figure 7. Game results under penalty increase for CC $\left(P_{b}\right)$ 


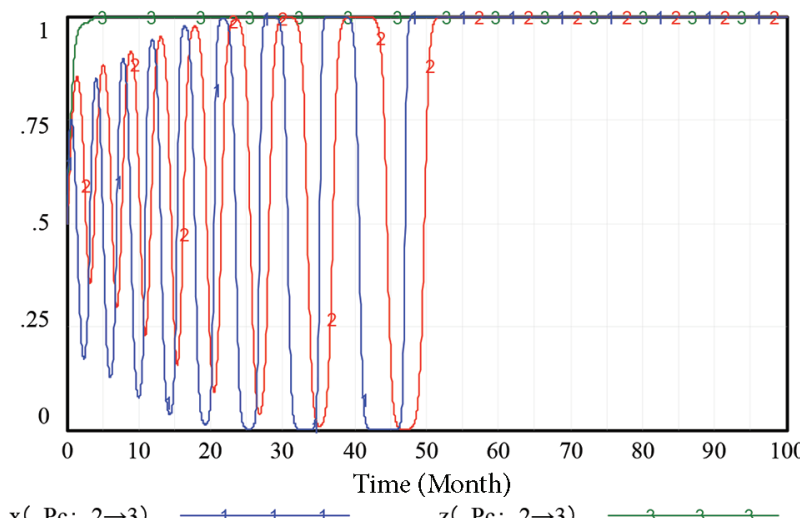

$\mathrm{x}(\mathrm{Pc}: 2 \rightarrow 3)$

$y(\operatorname{Pc}: 2 \rightarrow 3)$

Figure 8. Game results under penalty increase of CSE $\left(P_{c}\right)$

of the CC, although the CSE chooses strict execution of regulation duties.

The influence of reward is then investigated. After changing rewards of the CC and CSE, that is, $R_{b}$ changes from 2 to 0 and $R_{c}$ changes from 1 to 1.5 , the game results are shown in Figures 9 and 10. In China, ensuring construction quality is the CC's duty, so the CC's good performance usually entails no reward. However, the increasing reward of the CC could clearly reduce the fluctuating time of the game process, as demonstrated by the comparison of Figures 6 and 9. Figures 8 and 10 indicate that the increase in the CSE's penalty or reward does not influence the game process of the CC, which also proves the effect of the PO's supervision and the aborted regulation of the CSE.

To further verify the aborted regulation of the CSE, another simulation is made, specifically on how y changes when changes are made to $z$. A hypothesis is that $x=0.5$ and $z=0,0.1,0.5$ or 0.9 . The game result is shown in Figure 11. From Figure 11, the fluctuating time increases as $z$ increases, which proves the negative effect on the quality supervision system when the CSE executes regulation duties.

In summary, increasing penalty from the $\mathrm{PO}$ to the $\mathrm{CC}$ contributes to strengthening the deterrent of the PO, and increasing reward properly is conducive to giving full play to the enthusiasm and creativity of the CC, both of which

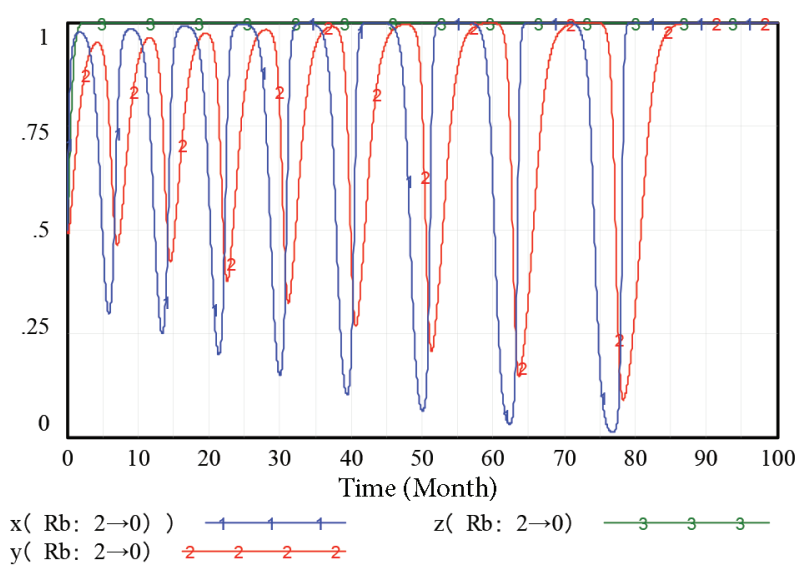

Figure 9. Game results under reward change for CC $\left(R_{b}\right)$

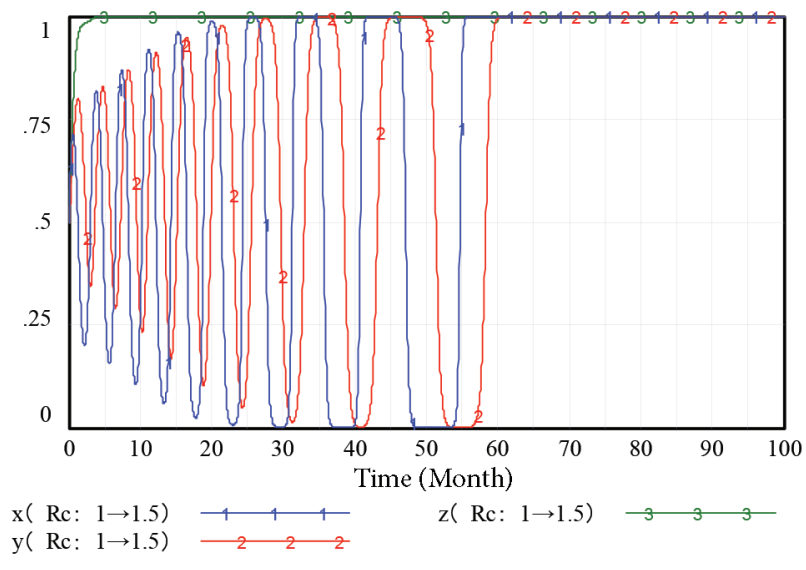

Figure 10. Game results under reward increase for CSE $\left(R_{c}\right)$

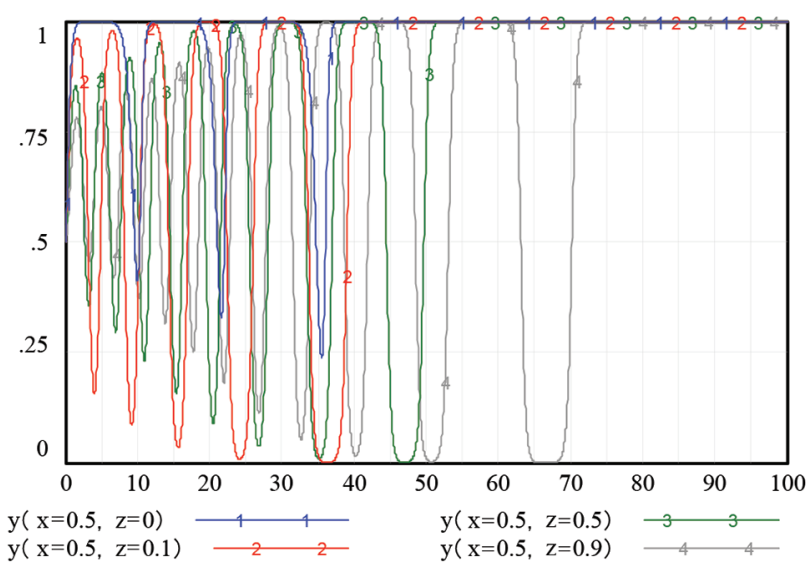

Figure 11. Game results when $z$ changes

could reduce the non-standardized construction ratio of the CC. However, the CSE chooses execution of regulation duties either by increasing penalty or reward, but neither variable has an influence on the CC. The reason for such finding is that the CSE has the right of supervision but no right to implement rewards or penalties on the CC in China, which renders the CC's strategy selection ineffective and may mislead the PO's supervision strategy.

\subsection{Stability control scenarios of the construction supervision system}

Repeated fluctuation of the SD model could be reduced by increasing the penalty and reward from the PO to the CC. However, the effect is not evident through reducing fluctuating time or forcing the game process to reach a certain state of stability. Therefore, studying the effective stability control scenarios on the fluctuations is necessary.

Many studies have proven that correlating penalties with their unlawful behavior ratio could effectively restrain the fluctuations (Cai 2011; Wang et al. 2011). In addition, evolutionary game theory could be used to identify the most appropriate penalty functions to inhibit unlawful behaviors (Estalaki et al. 2015). Some investigations have confirmed that increasing reward reduces the unlawful 


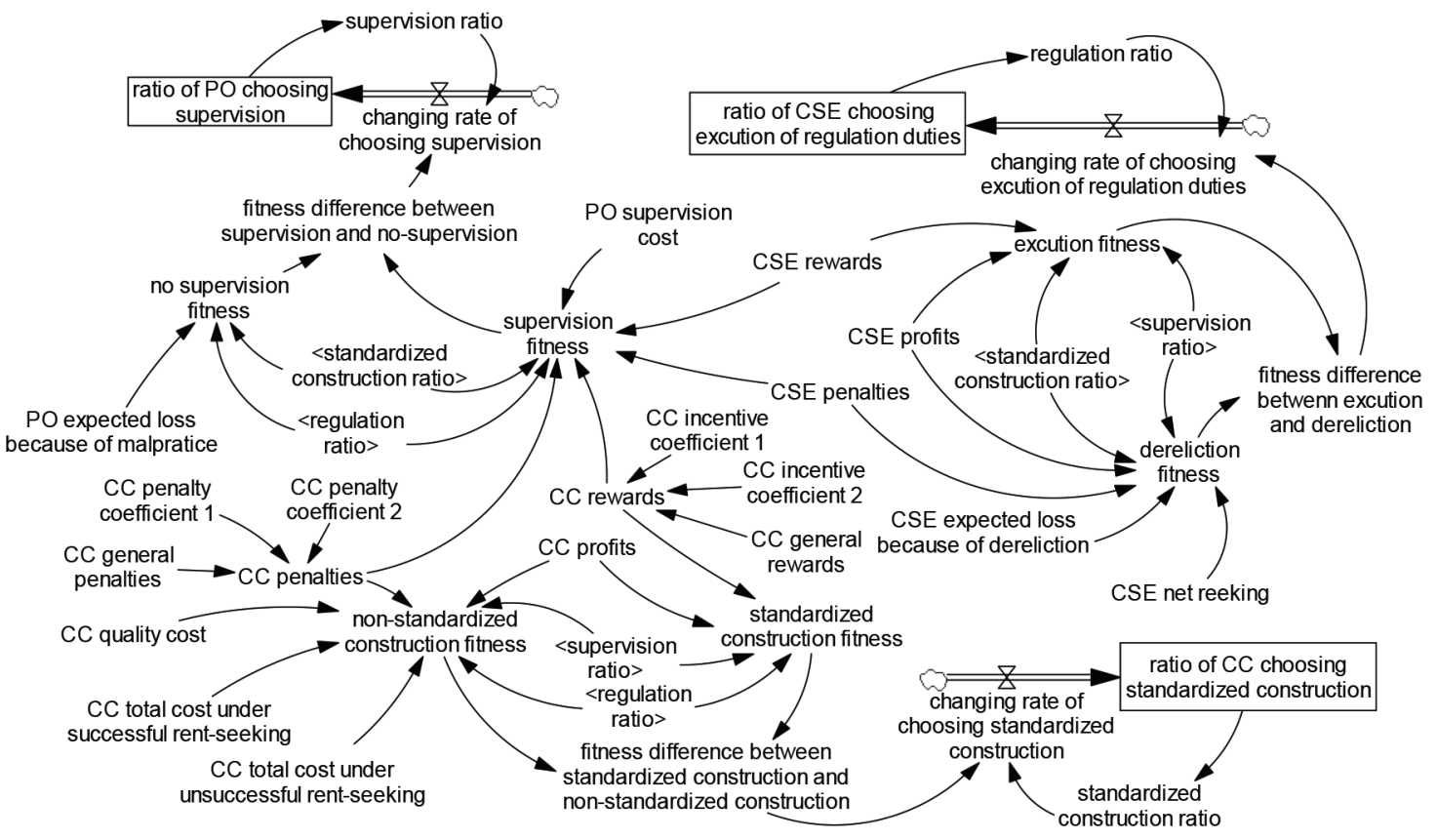

Figure 12. Evolutionary game SD model under the dynamic penalty-reward control scenario

behavior ratio (Cheng 2011; Li et al. 2017). Considering the verified negative impact of the CSE in the supervision process, an optimized dynamic penalty-incentive control scenario is proposed between the PO and CC, that is, the PO makes penalties and rewards dynamically according to the CC's standardized construction ratio, as shown in the following formula:

$$
\begin{aligned}
& P_{b}{ }^{\prime}=m_{1} * P_{b}(1-y)+m_{2} * \frac{C_{b}}{x} \\
& R_{b}{ }^{\prime}=n_{1} * R_{b} y+n_{2} * \frac{x}{C_{b}}
\end{aligned}
$$

where $m_{1}, m_{2}, n_{1}$, and $n_{2}$ represent the corresponding penalty coefficients or reward coefficients, which are all set to 1 in this study. Thus, the game SD model (Figure 3) is changed into the following figure (Figure 12) under the dynamic penalty-reward control scenario.

Results of the simulated evolutionary game process under the dynamic penalty-reward control scenario are shown below. When randomly considering the initial strategies $A=(x=0.5, y=0.5, z=0.5)$ and $B=(x=0.6, y=$ $0.2, z=0.4)$, the simulation results are shown in Figures 13 and 14 , respectively.

Simulation results show that the game approximately converges to $\lambda=(0,1,1)$, which presents an ideal ESS in which the CC will nearly choose standardized construction as their optimal strategy when the PO merely supervises at a small ratio. In addition, similar game results were obtained by randomly changing the strategies except for $x$, $y$, or $z=0$. Given the inclusion of $C_{b} / x$ in the formula, the ESS is $\lambda^{*}=(x, 1,1)$ as a result of $x \neq 0$, in which:

$$
\lambda^{*}=(x, 1,1), \lim _{t \rightarrow \infty} x=0 .
$$

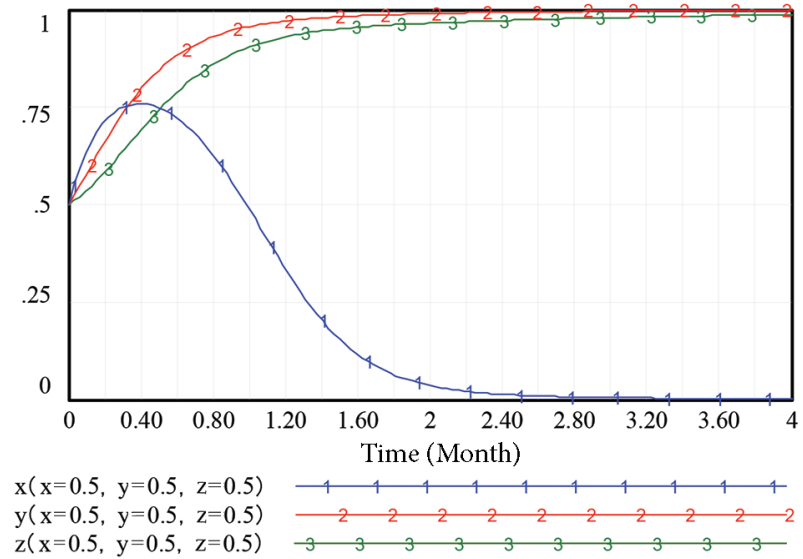

Figure 13. Game results under dynamic penalty-reward control scenario (Strategy A)

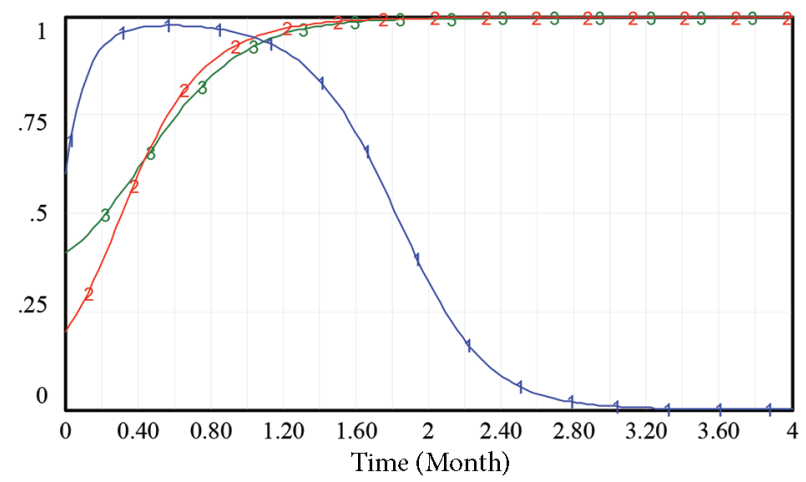

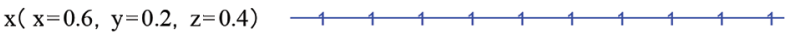
$y(x=0.6, y=0.2, z=0.4) \quad \begin{array}{lllllllll}2 & 2 & 2 & 2 & 2 & 2 & 2 & 2 & 2\end{array}$ $\mathrm{z}(\mathrm{x}=0.6, \mathrm{y}=0.2, \mathrm{z}=0.4) \quad 3 \quad 3 \quad 3-3 \quad \begin{array}{llllll}3 & 3\end{array}$

Figure 14. Game results under dynamic penalty-reward control scenario (Strategy B) 
However, whether the ESS is the true equilibrium solution remains unproven. Subsequently, a mathematical solution is applied to verify the above simulation results.
The initial values are plugged into simultaneous equations consisting of Eqns (5), (6), (7), and (8). The corresponding Jacobian matrix is as follows:

$$
J=\left(\begin{array}{ccc}
(1-2 x)(-3 y z-11 y-3 z+10) & x(1-x)(-3 z-11) & x(1-x)(-3 y-3) \\
6 y(1-y) & (1-2 y)(6 x-z-2) & -y(1-y) \\
3 z(1-z) & 1.5 z(1-z) & (1-2 z)(3 x+1.5 y-1)
\end{array}\right)
$$

When $\lambda^{*}=(x, 1,1)$ :

$$
J=\left(\begin{array}{ccc}
-7(1-2 x) & -14 x(1-x) & -6 x(1-x) \\
0 & -(6 x-3) & 0 \\
0 & 0 & -(3 x+0.5)
\end{array}\right) .
$$

Given that $\lim _{t \rightarrow \infty} x=0$ :

$$
\begin{aligned}
& a_{11}=\lim _{t \rightarrow \infty}-(7-2 x)=-7, a_{22}=\lim _{t \rightarrow \infty}-(6 x-3)=3, \\
& a_{33}=\lim _{t \rightarrow \infty}-(3 x+0.5)=-0.5 .
\end{aligned}
$$

Thus, the Jacobian matrix's determinant and trace are as follows:

$$
\begin{aligned}
& \operatorname{Det}(J)=a_{11} a_{22} a_{33}=(-7)^{*} 3^{*}(-0.5)=10.5>0 ; \\
& \operatorname{Tr}(J)=a_{11}+a_{22}+a_{33}=(-7)+3+(-0.5)=-4.5<0 .
\end{aligned}
$$

Consequently, the $\lambda=(x, 1,1)$ is the ESS, which is consistent with the simulated results.

In summary, the fluctuations and low efficiency of the construction supervision game system are improved under the dynamic penalty-reward control scenario, in which the CC will nearly choose standardized construction as their optimal strategy when the PO merely supervises at a small ratio.

\section{Discussions}

This paper proposes an SD model based on evolutionary game theory to study organizational problems in quality supervision, thereby bridging the gap caused by the scarcity of studies about the influence of participants' interaction on quality. The strategy selections of tripartite stakeholders were described with specific data in terms of expense targets, which facilitates the quantitative analysis of the stakeholders' interactions.

From the simulation process above, three results can be drawn:

1) The ESS does not exist in the initial interactions among the stakeholders, which reflects the organizational problems of quality supervision in China. Some studies have suggested that construction quality is hindered by a complex web of relationships among project participants (e.g. Chen, Luo 2014). Wang and Huang (2006) further indicated "relation/ guanxi" as the most important criterion of project success in China. These findings explain some causes of such problems but they are qualitative descriptions. By considering the balance between quality cost and economic benefits, this paper uses quantitative analysis to describe the strategy selections of tripartite stakeholders in terms of expense targets. Results confirm the negative interactions within the organization, causing an unsteady quality supervision system in China.

2) Changes in one external variable of the $P O$ (the degree of penalty and reward) considerably affects the CC's rate variable. Incentives positively impact the stakeholders' strategy selections toward quality, as verified in prior research (Tang et al. 2008; Meng, Gallagher 2012). However, the extent of influence to different project participants is poorly explored. Results show that the penalty and reward from the $\mathrm{PO}$ to the CC has a positive impact on the CC's standardized construction. By contrast, penalty and reward from the PO to the CSE do not influence the CC's standardized construction. In the compulsory supervision policy of China, when the CSE colludes with the CC, the CSE's penalty is counterbalanced by quality cost and the CSE's reward comes at the expense of sacrificing quality. For the asymmetric situation, although the CSE executes regulation duties, it is difficult for the PO to ascertain business bribery between the CSE and CC, which hinders the CC from fulfilling its quality duty. Given the positive and negative findings, this study emphasizes the important role of the $\mathrm{PO}$ and challenges the rationality of the CSE's position in quality supervision of China.

3) The dynamic penalty-reward scenario could effectively restrain the fluctuations and improve the stability of the proposed model. The scenario presents an optimized method for enhancing positive interactions among tripartite stakeholders. Compared with the change of penalty and reward from external conditions, this control scenario could better balance the interests of tripartite stakeholders by intensifying the internal regulation of the organization. Furthermore, the dynamic penalty-reward scenario provides an ideal ESS in which the CC could nearly choose standardized construction as their optimal strategy.

Simulation results with initial conditions show that the tripartite stakeholders' behaviors are unstable, which indicates the existence of problems in the current supervision mode of China. Subsequently changing the degree of penalty and reward from the PO to the CC has a great effect, whereas such change from the CSE to the CC does not. The latter finding suggests that the CSE's position is irrational under the Chinese compulsory 
supervision policy. Finally, the fluctuations could be well controlled under the dynamic penalty-reward scenario, which increases the stability in the interactions among the stakeholders and proves the necessity for changing the supervision mode. Based on these results, some suggestions could be made to optimize the procedures of quality supervision. First, compulsory supervision could be reconsidered by the Chinese government for its negative impacts. In China's quality supervision system, the existing quality supervision organizational structure needs to be reformed. Market-oriented supervision services could arise to break the interest link between the CSE and CC. The CSE could be transformed into a consulting service provider for the entire process, similar to their counterparts in some developed countries listed above. Then, the CC accomplishes project contracts under the direct supervision of the PO. The modified organizational structure will simplify relations among the tripartite stakeholders and restrain the rent-seeking behaviors of the CSE. Second, the PO could try to implement a dynamic penalty-reward scenario. This control scenario can help increase the degree of standardized construction by the CC. Thus, the efficiency and effect of quality supervision will be improved. Third, the PO can build a management system for special funds of quality supervision. If the CC performs poorly, they will incur penalties, which, in turn, will be included in the special funds. Conversely, the CC will get rewards from the funds. By establishing the special funds, the PO could better participate in construction quality management. By being dominated by the PO, the supervision mode will be accepted easily and the dynamic penalty-reward scenario will continue to work. In summary, an optimized program wherein the PO leads supervision, the CC is responsible for construction, and the CSE provides consulting services will be more suitable for a quality supervision organization in China, which helps reduce conflicts among the tripartite stakeholders and achieve common interests.

\section{Conclusions}

The performance of a quality supervision system is directly related to whether the quality goal of the project could be achieved. Existing studies have focused on the impact of the work quality of certain participants on construction performance but ignore the interactions among stakeholders. By establishing an SD model based on evolutionary game theory, such interactions have been described and analyzed in the quality supervision system in China. Results show that the ESS does not exist in the initial interactions among tripartite stakeholders. Accordingly, an effective stability control scenario was proposed on the analysis of the influence of external variables. From theoretical aspects, evolutionary game theory was used to simulate the dynamic interactions among tripartite stakeholders, which could overcome the limitation of the traditional static game pertaining to its limitation in analyzing complex dynamic problems. Moreover, the strategy changes of the tripartite stakeholders were quantitatively analyzed to understand the impacts of interactions. Furthermore, the proposed dynamic penalty-reward scenario was found to balance the interests of the tripartite stakeholders, thereby meeting the requirement of quality cost. From the practical aspects, the results reflect the extant organizational problems in the Chinese quality supervision system. The following suggestions are provided for improving the efficiency and effectiveness of quality supervision. First, the compulsory supervision policy can be repealed and the role of the CSE could be transformed into a project consulting service provider. The CSE could better fulfill consultation obligations as an independent third party. In addition, the function of the PO needs to be reinforced by implementing a dynamic penalty-reward scenario and establishing special funds. The PO's authority can help regulate the construction behaviors of the CC. Finally, an optimized quality supervision organization could be established wherein the PO leads the supervision, the $\mathrm{CC}$ is responsible for construction, and the CSE provides consulting services. At present, the Chinese government has put forward a series of policies and measures to improve compulsory supervision and promote engineering consulting development, which proves the feasibility of the above suggestions to a certain extent. Nevertheless, some limitations still exist that need to be addressed. For instance, the initial values of the external variables obtained from the Chinese Construction Industry Statistical Yearbook could be of hysteretic nature. If these initial values can instead be ascertained by collecting data from on-site quality documents, then the simulation results will be more accurate and practical. Furthermore, an assumption was made whereby the PO's ability of supervision is sufficiently powerful. However, the ability of supervisors is bounded and errors are inevitable. If the supervision error rate could be obtained and analyzed in the proposed SD model, then the simulation process will be more rational. Future research can also incorporate to the model the roles which represent the regulation departments of the government to further explore the interactions within and across the construction organization.

\section{Funding}

This work was supported by the Fundamental Research Funds for the Central Universities, China University of Geosciences (Wuhan) under Grant [number 170649]; the Research Foundation of Humanities and Social Sciences of Ministry of Education of China under Grant [number 15YJA630019]; the National Natural Science Foundation of China under Grant [number 71573237]; China Institute of Geo-environment Monitoring under Grant [number 0001212016CC60013].

\section{Author Contributions}

Shengyu Guo conceived the study and were responsible for the design and development of the methodology. Pan Zhang was responsible for establishment and simulation of 
the Game+SD model. Jianying Yang was responsible for data collection and interpretation. Pan Zhang wrote the first draft of the article.

\section{Disclosure statement}

Authors confirm that all of the content, figures (charts, photographs, etc.), and tables in the submitted manuscript work are original work created by the authors and no any competing financial, professional, or personal interests from other parties.

\section{References}

Abdul-Aziz, A. R. 2002. The realities of applying total quality management in the construction industry, Structural Survey 20(2): 88-96. http://dx.doi.org/10.1108/02630800210433864

Alzahrani, J. I.; Emsley, M. W. 2013. The impact of contractors' attributes on construction project success: A post construction evaluation, International Journal of Project Management 31(2): 313-322. https://doi.org/10.1016/j.ijproman.2012.06.006

Arditi, D.; Gunaydin, H. M. 1997. Total quality management in the construction process, International Journal of Project Management 15(4): 235-243.

https://doi.org/10.1016/S0263-7863(96)00076-2

Bosché, F. 2010. Automated recognition of 3d cad model objects in laser scans and calculation of as-built dimensions for dimensional compliance control in construction, Advanced Engineering Informatics 24(1): 107-118. https://doi.org/10.1016/j.aei.2009.08.006

Cai, L. R. 2011. Multi-person evolutionary game of environment pollution based on system dynamics, Application Research of Computers 28(8): 2982-2986. https://doi.org/10.3969/j.issn.1001-3695.2011.08.050

Chan, A. P. C.; Scott, D.; Chan, A. P. L. 2004. Factors affecting the success of a construction project, Journal of Construction Engineering and Management 130(1): 153-155. https://doi.org/10.1061/(ASCE)0733-9364(2004)130:1(153)

Chen, L.; Luo, H. 2014. A BIM-based construction quality management model and its applications, Automation in Construction 46: 64-73. https://doi.org/10.1016/j.autcon.2014.05.009

Chen, P.; Partington, D. 2004. An interpretive comparison of Chinese and Western conceptions of relationships in construction project management work, International Journal of Project Management 22(5): 397-406.

https://doi.org/10.1016/j.ijproman.2003.09.005

Cheng, Y.; Chen, Y.; Wei, R.; Luo, H. 2015. Development of a construction quality supervision collaboration system based on a saas private cloud, Journal of Intelligent \& Robotic Systems 79(3-4): 613. https://doi.org/10.1007/s10846-014-0108-8

Cheng, M. 2011. Game study on construction safety supervision based on system dynamics, China Safety Science Journal 21(12): 73-81. https://doi.org/10.3969/j.issn.1003-3033.2011.12.011

Dikmen, I.; Birgonul, M. T.; Kiziltas, S. 2005. Strategic use of quality function deployment (QFD) in the construction industry, Building and Environment 40(2): 245-255. https://doi.org/10.1016/j.buildenv.2004.07.001

Doloi, H.; Iyer, K.; Sawhney, A. 2011. Structural equation model for assessing impacts of contractor's performance on project success, International Journal of Project Management 29(6): 687-695. https://doi.org/10.1016/j.ijproman.2010.05.007
Duan, W.; Li, C.; Zhang, P.; Chang, Q. 2016. Game modeling and policy research on the system dynamics-based tripartite evolution for government environmental regulation, Cluster Computing 19(4): 2061-2074.

https://doi.org/10.1007/s10586-016-0642-1

Eriksson, P. E.; Westerberg, M. 2011. Effects of cooperative procurement procedures on construction project performance: A conceptual framework, International Journal of Project Management 29(2): 197-208. https://doi.org/10.1016/j.ijproman.2010.01.003

Estalaki, S. M.; Abed-Elmdoust, A.; Kerachian, R. 2015. Developing environmental penalty functions for river water quality management: application of evolutionary game theory, Environmental Earth Sciences 73(8): 4201-4213. https://doi.org/10.1007/s12665-014-3706-7

Friedman, D. 1991. Evolutionary games in economics, Econometrica 59(3): 637-666. https://doi.org/10.2307/2938222

Harris, F.; Mccaffer, R. 2013. Modern construction management. John Wiley \& Sons.

Hoonakker, P.; Carayon, P.; Loushine, T. 2010. Barriers and benefits of quality management in the construction industry: An empirical study, Total Quality Management \& Business Excellence 21(9): 953-969. https://doi.org/10.1080/14783363.2010.487673

Huang, W.; Feng, X.; Zhao, Z. 2008. Establishment and application of project quality management system of the owner, Construction Economy. https://doi.org/10.14181/j.cnki.1002-851x.2008.s2.045

Jha, K. N.; Iyer, K. C. 2006. Critical factors affecting quality performance in construction projects, Total Quality Management \& Business Excellence 17(9): 1155-1170. http://dx.doi.org/10.1080/14783360600750444

Kanji, G. K.; Wong, A. 1998. Quality culture in the construction industry, Total Quality Management 9(4-5): 133-140. http://dx.doi.org/10.1080/0954412988758

Khanzadi, M.; Eshtehardian, E.; Chalekaee, A. 2016. A game theory approach for optimum strategy of the owner and contractor in delayed projects, Journal of Civil Engineering and Management 22(8): 1066-1077. http://dx.doi.org/10.3846/13923730.2016.1210222

Li, Y. Z.; Dong, L. F.; Wu, Z. W. 2017. Analysis of an evolutionary game on information sharing of E-government based on system dynamics, Journal of University of Electronic Science \& Technology of China. https://doi.org/10.14071/j.1008-8105(2017)01-0035-08

Li, Y.; Wang, X.; Wang, Y. 2016. Using bargaining game theory for risk allocation of public-private partnership projects: Insights from different alternating offer sequences of participants, Journal of Construction Engineering and Management 143(3): 04016102. https://doi.org/10.1061/(ASCE)CO.1943-7862.0001249

Liu, Q.; Li, X.; Hassall, M. 2015. Evolutionary game analysis and stability control scenarios of coal mine safety inspection system in china based on system dynamics, Safety Science 80: 13-22. https://doi.org/10.1016/j.ssci.2015.07.005

Loushine, T. W.; Hoonakker, P. L. T.; Carayon, P.; Smith, M. J. 2006. Quality and safety management in construction, Total Quality Management \& Business Excellence 17(9): 1171-1212. http://dx.doi.org/10.1080/14783360600750469

Love, P. E. D.; Li, H.; Irani, Z.; Faniran, O. 2000. Total quality management and the learning organization: A dialogue for change in construction, Construction Management and Economics 18(3): 321-331. https://doi.org/10.1080/014461900370681 
Love, P. E.; Irani, Z. 2003. A project management quality cost information system for the construction industry, Information \& Management 40(7): 649-661. https://doi.org/10.1016/S0378-7206(02)00094-0

Lu, W.; Huang, G. Q.; Li, H. 2011. Scenarios for applying rfid technology in construction project management, Automation in Construction 20(2): 101-106.

https://doi.org/10.1016/j.autcon.2010.09.007

Meng, X. 2012. The effect of relationship management on project performance in construction, International Journal of Project Management 30(2): 188-198.

https://doi.org/10.1016/j.ijproman.2011.04.002

Meng, X.; Gallagher, B. 2012. The impact of incentive mechanisms on project performance, International Journal of Project Management 30(3): 352-362.

https://doi.org/10.1016/j.ijproman.2011.08.006

Nasirzadeh, F.; Mazandaranizadeh, H.; Rouhparvar, M. 2016. Quantitative risk allocation in construction projects using cooperative-bargaining game theory, International Journal of Civil Engineering 14(3): 161-170. https://doi.org/10.1007/s40999-016-0011-8

O'Brien, J. J. 2013. Construction inspection handbook: Quality assurance/quality control. Springer Science \& Business Media.

Parsapour-Moghaddam, P.; Abed-Elmdoust, A.; Kerachian, R. 2015. A heuristic evolutionary game theoretic methodology for conjunctive use of surface and groundwater resources, Water Resources Management 29(11): 3905-3918. https://doi.org/10.1007/s11269-015-1035-6

Pheng, L. S.; Teo, J. A. 2004. Implementing total quality management in construction firms, Journal of Management in Engineering 20(1): 8-15. https://doi.org/10.1061/(ASCE)0742-597X(2004)20:1(8)

Roca, C. P.; Cuesta, J. A.; Sánchez, A. 2009. Evolutionary game theory: Temporal and spatial effects beyond replicator dynamics, Physics of Life Reviews 6(4): 208-249. https://doi.org/10.1016/j.plrev.2009.08.001

Sacks, R.; Harel, M. 2006. An economic game theory model of subcontractor resource allocation behaviour, Construction Management and Economics 24(8): 869-881. http://dx.doi.org/10.1080/01446190600631856

San Cristóbal, J. R. 2015. The use of game theory to solve conflicts in the project management and construction industry, International Journal of Information Systems and Project Management 3(2): 43-58. http://dx.doi.org/10.12821/ijispm030203

Sullivan, K. T. 2011. Quality management programs in the construction industry: Best value compared with other methodologies, Journal of Management in Engineering 27(4): 210-219. http://dx.doi.org/10.1061/(ASCE)ME.1943-5479.0000054

Taylor, T.; Counsell, J.; Gill, S. 2013. Energy efficiency is more than skin deep: Improving construction quality control in new-build housing using thermography, Energy and Buildings 66: 222-231. https://doi.org/10.1016/j.enbuild.2013.07.051

Talib, F.; Rahman, Z.; Qureshi, M. N. 2011. Analysis of interaction among the barriers to total quality management implementation using interpretive structural modeling approach, Benchmarking: An International Journal 18(4): 563-587. https://doi.org/10.1108/14635771111147641

Tang, W.; Qiang, M.; Duffield, C. F.; Young, D. M.; Lu, Y. 2008. Incentives in the chinese construction industry, Journal of Construction Engineering and Management 134(7): 457-467. http://dx.doi.org/10.1061/(ASCE)0733-9364(2008)134:7(457)
Tchidi, M. F.; He, Z.; Li, Y. B. 2012. Process and quality improvement using six sigma in construction industry, Journal of Civil Engineering and Management 18(2): 158-172. http://dx.doi.org/10.3846/13923730.2012.657411

Tian, Y.; Govindan, K.; Zhu, Q. 2014. A system dynamics model based on evolutionary game theory for green supply chain management diffusion among chinese manufacturers, Journal of Cleaner Production 80: 96-105. https://doi.org/10.1016/j.jclepro.2014.05.076

Toor, S.-U.-R.; Ogunlana, S. O. 2010. Beyond the "iron triangle": Stakeholder perception of key performance indicators (KPIs) for large-scale public sector development projects, International Journal of Project Management 28(3): 228-236. https://doi.org/10.1016/j.ijproman.2009.05.005

Vlachos, D.; Georgiadis, P.; Iakovou, E. 2007. A system dynamics model for dynamic capacity planning of remanufacturing in closed-loop supply chains, Computers \& Operations Research 34(2): 367-394. https://doi.org/10.1016/j.cor.2005.03.005

Wang, H.; Cai, L.; Zeng, W. 2011. Research on the evolutionary game of environmental pollution in system dynamics model, Journal of Experimental \& Theoretical Artificial Intelligence 23(1): 39-50. http://dx.doi.org/10.1080/0952813X.2010.506300

Wang, Y.; Ding, H.; Xiao, Y. 2014. Game analysis on rent-seeking behavior of three participants in overseas engineering project, in Seventh International Joint Conference on Computational Sciences and Optimization, 4-6 July 2014, Beijing, China, 79-82. https://doi.org/10.1109/CSO.2014.24

Wang, X.; Huang, J. 2006. The relationships between key stakeholders' project performance and project success: Perceptions of Chinese construction supervising engineers, International Journal of Project Management 24(3): 253-260. https://doi.org/10.1016/j.ijproman.2005.11.006

Weibull, J. W. 1997. Evolutionary game theory. MIT press.

Wong, A. 1999. Total quality management in the construction industry in Hong Kong: A supply chain management perspective, Total Quality Management 10(2): 199-208. http://dx.doi.org/10.1080/0954412997956

Zhang, C. 2016. Small and medium-sized enterprises closed-loop supply chain finance risk based on evolutionary game theory and system dynamics, Journal of Shanghai Jiaotong University (Science) 21(3): 355-364. http://dx.doi.org/10.1007/s12204-016-1733-0 